\title{
Recipes for Waste-Tooling: Using Food Waste in Design
}

\author{
Berfin Evrim \\ Pennsylvania State University | USA | bpe5045@psu.edu \\ Grant Davis \\ Pennsylvania State University | USA | gkd3@psu.edu \\ Josh Tubay \\ Pennsylvania State University | USA | jdt5331@psu.edu \\ Benay Gursoy \\ Pennsylvania State University | USA | bug61@psu.edu
}

\begin{abstract}
In this research, we propose an alternate consumption cycle in which the traditional landfill waste disposal model is averted by developing design objects that are fabricated with household biowaste materials. Food decomposition in landfills not only wastes the energy and emissions input into the original production process, but also releases methane. By rerouting this waste for secondary use as novel design objects and tools, in this research we seek to prevent some amounts of household biowaste from reaching landfills. This process, that we call waste-tooling, repurposes food waste to make kitchen tools by employing different fabrication strategies.
\end{abstract}

Keywords: Circular economy; Biowaste; 3D printing.

\section{INTRODUCTION}

Research has shown that around one third of the world's food is lost or wasted every year, and that the food we waste produces $8 \%$ of global $\mathrm{CO} 2$ emissions. The Food and Agriculture Organization of the United Nations (FAO) defines food waste as "the decrease in the quantity or quality of food resulting from decisions and actions by retailers, food service providers, and consumers". According to this framework, there are three major sources of food wastage: 1) fresh foods that are removed from the supply chain because of their deviations from what is considered normal in terms of shape, size and color, 2) foods that are discarded by retailers and consumers when they are close to their best-before date, and 3) unused and leftover foods that are discarded from household kitchens and eating establishments. With this project, the authors tapped into the latter source of food wastage. We developed alternative recipes to make kitchen tools in which the ingredients were unused, leftover, and discarded foods from household kitchens. We call this process "waste-tooling". Waste-tooling can prevent food waste from ending up in landfills where it decomposes and releases methane, a greenhouse gas that is more potent than $\mathrm{CO} 2$. This project presents an exploration of recipes that consist of food waste and molding processes, which can be pursued in any household to fabricate kitchen tools.

\section{BACKGROUND}

Food waste is a global problem, which has a huge impact on climate change due to greenhouse emissions from anaerobic digestion. Melikoglu (2013) claims that food waste will increase in 25 years with population growth. Cities produce about 1.3 billion tons of solid waste every year (Clark, 2017). Food processing companies generate large amounts of waste all over the world, and food supply chains produce more than half of the food waste. All this waste can endanger public safety if it is not managed properly. As a solution, researchers have been exploring ways to reuse biological waste as a fabrication material.

$3 \mathrm{D}$ printing is an additive manufacturing technique that can be adaptable to reuse waste materials. Walters et. al (2011) experimented with alternative food-waste materials for 3D printing and compared three prototyping techniques: rapid tooling, powder and binder 3D printing, and extrusionbased rapid manufacturing. The researchers changed the Z-corp powder of a Z-corp printer to sugar and printed a "sweet tooth". Additionally, they tested different mixtures of caster, icing and silk sugars, and maltodextrin. Additionally, there are also other studies that specifically focus on coffee ground waste to fabricate architectural material such as bricks (D Eliche-Quesada et al., 2011).

According to Jagdale (2019), global production of coffee reached 11-13 million tons. The brewed coffee waste is 380,000 tons annually, which causes environmental pollution because of the high content of organic matter as caffeine, free phenols, and tannins (polyphenols), and acid content. This problem leads to studies that focused on the reuse of coffee waste. D Eliche-Quesada et. al (2011) studied a mixture of coffee ground waste with raw clay to produce bricks by compressing, dehydrating, and firing the samples. They suggested that coffee ground waste is effective for pore formation in the clay body and it improves insulating properties. As a result of their experiments, they found out that the bricks made of higher amounts of coffee grounds have better mechanical, physical, and thermal 
properties. Other than clay, there are other materials that can be combined with coffee waste. Canavarro et. al (2017) presented a novel fabrication technique for the reuse of leftovers to obtain a moldable material made of coffee grounds and a powder binder. They used molding and 3D printing methods to produce the final material. As a binder, they tested epoxy resin, starch, pine resin, wax, and polylactic acid (PLA). They received the best results with the combination of PLA and coffee grounds. In this study, various ingredients were used to determine the most successfully bound mixture to fabricate tools out of various food waste.

\section{METHODOLOGY: RECIPE EXPLORATION AND FORMWORK DESIGN}

\section{INGREDIENTS AND PROCESS OVERVIEW}

The process of formulating mixture recipes contained four main steps: 1) the selection of the food waste ingredients and liquid binder; 2) the processing of those ingredients to create a dry, mixable powder; 3 ) the mixing and curing of the test recipe; 4) post-processing the final samples and analysis. Rael and San Fratello (2018) provided sample recipes, which used a sugar mixture of granulated and powdered sugar and an alcohol-based binder. Using this as a jumping off point, our experiments incorporated various ratios of processed food waste with the sugar mixture that are bounded using either the alcohol-based solution or sake rice wine. Sake and the $10 \%$ isopropyl alcohol to $90 \%$ water solution provided by Rael and San Fratello (2018) proved to be equally effective when binding the same powder, thus the alcohol-solution was used en masse for the purpose of cost-efficiency.

The project was initially developed for a design exhibition in Turkey. Therefore, the selection of the potential food powders were based on two criteria: one, whether the candidate material was a common food item available in Turkey with easily harvestable waste, and two, whether it provided particular color and/or cultural relevance. Five food-based powders were subsequently introduced for consideration. Extra-fine ground Turkish Coffee, both pre and post brew was a primary study material. Additionally, eggshells, boiled, crushed, and washed with vinegar were also tested. Common Turkish spices such as Paprika, Cumin, and Curry were also included in the study. All of the candidate materials were processed into a dry fine powder, then mixed in varying ratios with the sugar mixture, as well as the additional binding powders of Corn Starch and Maltodextrin. The mixed samples were then spread into a thin layer on test plates and sprayed with a set amount of alcohol solution. The test samples were then briefly dehydrated before being left exposed to the air overnight to harden. Following the curing period, the test samples were either categorized as fully bound, indicating a completely homogenous and rigid mass was achieved; semi-bound, indicating a partially homogeneous rigid mass; or unbound, indicating failure to harden or bind. Successful tests were then coated with Pullulan Film, a post-processing agent to help maintain surface smoothness and rigidity.

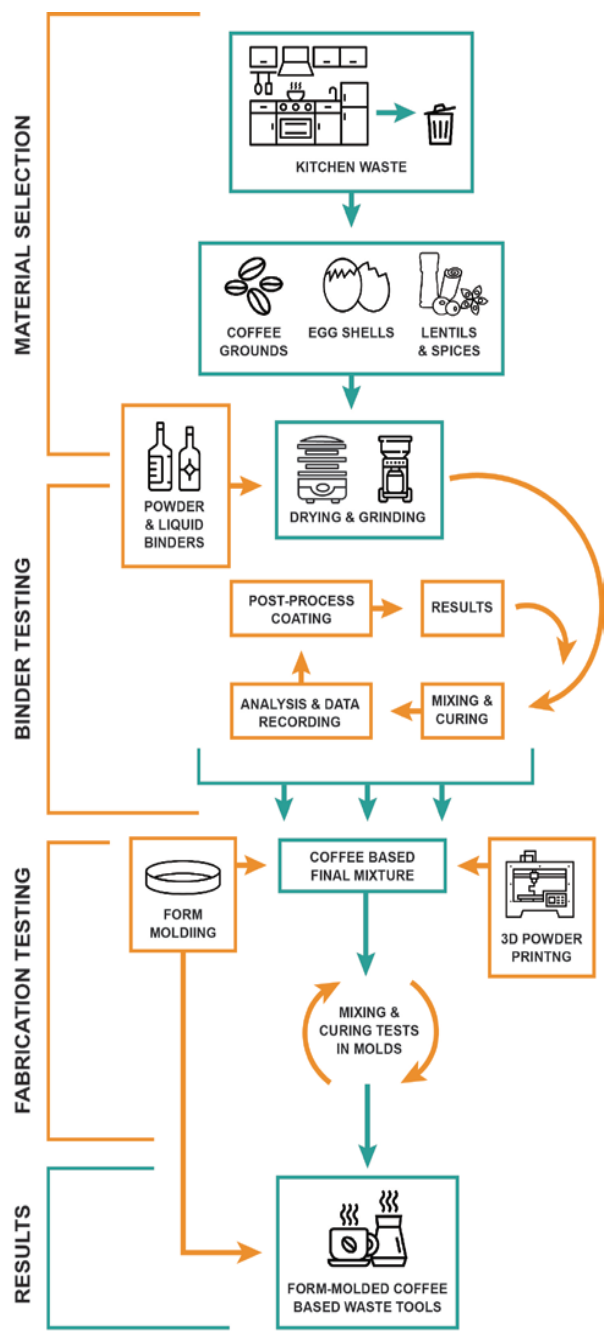

Figure 1: Process Overview

\section{PRE-PROCESSING FOOD MATERIALS}

In order to blend successfully with the binding powder (sugar, maltodextrin, etc.) it was necessary to pre-process some of the food waste candidates to create a fine powder. Paprika, Cumin, and Curry, were all available in a powdered form and were not used post-consumer, thus no pre-processing was needed. Coffee and eggshells, on the other hand, required varying processing methods depending on their original form. For the finely-ground Turkish Coffee, when the sample was tested without first being used for brewing, it did not need any processing other than the original grinding of the beans. On the other hand, coffee grounds, which have been brewed were dehydrated, then re-ground to return to a dry, powdered state. 


\section{ADAPTING THE TOOLING PROCESS FOR MOLDING}

During the early development and material experiments, the goal was to find powder binder mixtures which activated when mixed with non-adhesive liquid binder in a 3D printing process. Thus, glue-based liquid binding solutions were not initially considered as they cannot be processed through a powder-based printing machine. For example, the isopropyl alcohol binding solution, which was selected remains liquid until it is introduced to the maltodextrin or sugar in the powder mixture, thus preventing clogging in the powder-based 3D printer. Likewise, the initial testing process of spreading the powder mixtures on test plates and spraying on the liquid binder was intended to mimic the 3D printing process.

With the advent of the COVID-19 Pandemic, access to our research team's hacked powder printer was limited by social-distancing regulations at the Pennsylvania State University. Armed with at-home FDM 3D printers capable of producing reusable plastic formworks, our team pursued a secondary line of research making use of the alreadytested powder mixtures to create form-molded tools rather than 3D printed ones. Without the limitations on liquid binders involved with using a powder-based 3D printer, glue-based liquid binding agents were reconsidered. Flexibility in powdered material choice was increased by incorporating a known binding agent into the liquid formula. When the initial powder and alcohol recipes were transferred from a layering assembly process (3D printing) to a molding process, stability and cracking was an issue. However, with the addition of glue to the liquid binding formula, the rigidity of the form-cast tests was increased significantly.

The addition of form-molding to our research has proved advantageous as it democratizes the waste-tooling process for at-home experimentation. Casting molds can be fashioned of a variety of materials, not just $3 D$ printed plastics, hypothetically allowing an at home user to manufacture their own molds out of the material of their choice, and even using available kitchen tools. This, combined with the nominal availability of the powdered materials and liquid binders opens up waste tooling to a wider audience.

\section{POST-PROCESSING MIXTURES}

The recipes are made of easily accessible materials that can be found in most kitchens. The goal of this research is to allow anyone to make their own kitchen tools at their home using food waste. The plastic formworks that we designed and $3 \mathrm{D}$ printed have an outer and inner mold. The formworks are fabricated using two different methods. The first method is $3 \mathrm{D}$ printing an inner and outer mold. The advantage of using this two part molding method is higher shape accuracy. However, it takes more time to fabricate the molds. The second method is vacuum forming. For this method, the actual form needs to be placed inside the vacuum forming machine to create a negative mold. The advantage of this fabrication technique is a reduction in fabrication time.

This research focused on the first formwork fabrication method that requires $3 \mathrm{D}$ printing the inner and outer molds. The molds are printed of Polylactic Acid (PLA) and Thermoplastic Elastomer (TPE). The outer mold of complex geometries has two pieces that connect together.
After 3D printing the molds, lacquer is applied on the printed formworks to smoothen the surfaces for easier mold release purposes (Figure 1).

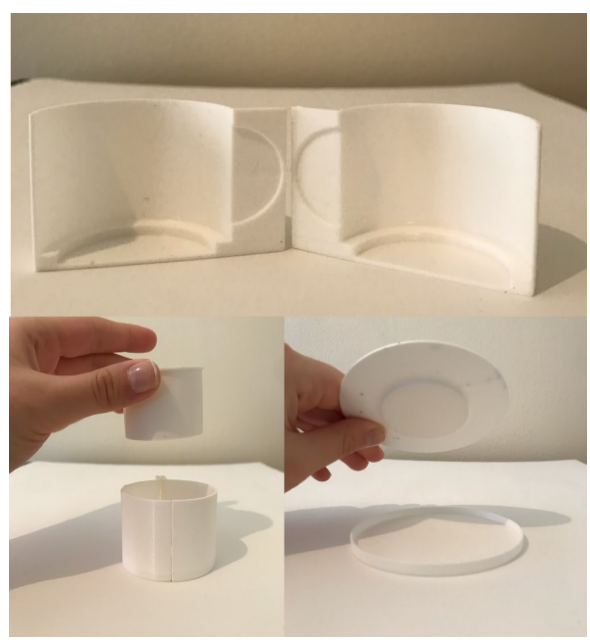

Figure 2: 3D printed formworks out of PLA

The next step is the preparation of the powder mixture and binder. The powder mixture is made of $50 \%$ coffee grounds and $\% 50$ maltodextrin. While exploring the binder options, three parts of water and one part of isopropyl alcohol resulted in the mixture taking the shape of the mold, however, the final result cracked easily under compression. Consequently, one part of PVA-based synthetic glue was added into the binder mixture. The paste has great resistance to compression and bound the powder mixture effectively.

After deciding on the powder binder, the glue-based liquid binder is added to the powder mixture until the powder mixture is saturated. A release agent is applied to the formwork and then, the paste is added to the mold and pressed with the inner mold. The wait time for the paste to dry is at least 48 hours.

\section{RESULTS}

\section{RECIPE RESULTS}

Throughout our research process, thirty-nine individual powder mixtures were tested; all with the isopropyl alcohol based liquid binder and some with the addition of glue for formwork molding tests. The majority of the material testing was conducted with the anticipation of using the powderbased $3 D$ printer for fabrication, thus the powders were spread on test plates and sprayed with the alcohol binder to simulate the $3 \mathrm{D}$ printing process. The results were categorized into three main groups based on the level of cohesion: bound, indicating the creation of a singular solid mass resulting from the application of the liquid binder to the powder, semi-bound, indicating the creation of varying solid chunks, not necessarily bound to one another in a solidary mass, and unbound, indicating complete failure to create a solid with the mixture. Of the thirty-nine tests, nine resulted in bound solids, fifteen resulted in semi-bound chunks, and fifteen resulted in unbound mixtures where no adhesion occurred (Figure 2). 


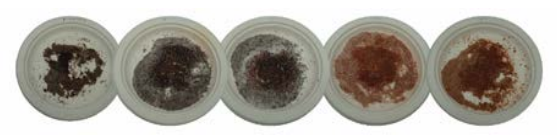

Figure 3: Example mixtures after curing

The results of our testing showed several common patterns indicating which powder additives resulted in a mixture in which the food waste and binders were most cohesively bound into a solid. Of the nine test results classified as bound, all included maltodextrin as the primary powder binding agent. Several also included the dry powdered form of our post-processing binding agent pullulan; the combination of maltodextrin and pullulan resulted in highly solidified mixtures. The tests which resulted in unbound mixtures also revealed interesting trends. For example, none of the lentil-based powder mixtures resulted in a bound formula, even when mixed with maltodextrin and a sugar mixture, two materials which bind strongly on their own. Furthermore, eggshells processed with their membranes intact (SWM-shells with membrane), did not bind, especially when mixed with a non-binding powder like a spice or cocoa. The semi-bound test results represented a broad mix where powders that may not have bound otherwise, were semi-solidified by the addition of a powerful binding agent like maltodextrin.

Table 1: Mixture recipes

\begin{tabular}{|ll|}
\hline $\begin{array}{l}\text { Mixture } \\
\text { Name }\end{array}$ & Mixture Contents \\
\hline GSPS & $\begin{array}{l}\text { 2 Parts Granulated Sugar, 1 Part Powdered } \\
\text { Sugar }\end{array}$ \\
\hline MDX & Maltodextrin Powder \\
\hline Pullulan & Powdered Binding Agent \\
\hline CES & Clean Egg Shells \\
\hline HBES & Hard Boiled Egg Shells \\
\hline SWM & Shells With Membrane \\
\hline CCPSGS & $50 / 50$ Cocoa Powder to GSPS mixture \\
\hline $\begin{array}{l}\text { Alcohol } \\
\text { Binder }\end{array}$ & $\begin{array}{l}280 \mathrm{ml} \text { isopropyl alcohol (91\%), 920 ml distilled } \\
\text { water }\end{array}$ \\
\hline
\end{tabular}

Table 2: Recipes and results

\begin{tabular}{|ll|}
\hline Ingredients & Result \\
\hline 1 Part GSPS, 1 Part MDX & Semi-Bound \\
\hline 1 Part Paprika, 1 Part MDX & Semi-Bound \\
\hline 1 Part GSPS, 1 Part MDX, 1 Part Paprika & Semi-Bound \\
\hline $\begin{array}{ll}\text { 1 Part GSPS, 1 Part MDX, 1 Part Fine } \\
\text { Coffee }\end{array}$ & Semi-Bound \\
\hline $\begin{array}{l}\text { 2 Parts GSPS, 1 Part MDX, 1 Part Fine } \\
\text { Coffee }\end{array}$ & Semi-Bound \\
\hline $\begin{array}{l}\text { 1 Part GSPS, 2 Parts MDX, 1 Part Fine } \\
\text { Coffee }\end{array}$ & Unbound \\
\hline 1 Part MDX, 1 Part Fine Coffee & Bound \\
\hline 1 Part MDX, 1 Part Green Lentil & Unbound \\
\hline 1 Part MDX, 1 Part Red Lentil & Unbound \\
\hline
\end{tabular}

\begin{tabular}{|c|c|}
\hline 1 Part GSPS, 1 Part Green Lentil & Unbound \\
\hline 1 Part GSPS, 1 Part Red Lentil & Semi-Bound \\
\hline $\begin{array}{l}1 \text { Part MDX, } 1 \text { Part GSPS, } 1 \text { Part Green } \\
\text { Lentil }\end{array}$ & Unbound \\
\hline $\begin{array}{l}1 \text { Part MDX, } 1 \text { Part GSPS, } 1 \text { Part Red } \\
\text { Lentil }\end{array}$ & Unbound \\
\hline 1 Part Pectin, 1 Part Fine Coffee & Unbound \\
\hline $\begin{array}{l}1 \text { Part Pectin, } 1 \text { Part GSPS, } 1 \text { Part Fine } \\
\text { Coffee }\end{array}$ & Unbound \\
\hline $\begin{array}{l}1 \text { Part Pectin, } 1 \text { Part MDX, } 1 \text { Part Fine } \\
\text { Coffee }\end{array}$ & Semi-Bound \\
\hline $\begin{array}{l}1 \text { Part Pectin, } 1 \text { Part MDX, } 1 \text { Part GSPS, } \\
1 \text { Part Fine Coffee }\end{array}$ & Unbound \\
\hline $\begin{array}{l}1 \text { Part Pectin, } 1 \text { Part MDX, } 1 \text { Part GSPS, } \\
2 \text { Part Fine Coffee }\end{array}$ & Semi-Bound \\
\hline $\begin{array}{l}1 \text { Part Pectin, } 2 \text { Part GSPS, } 1 \text { Part Fine } \\
\text { Coffee }\end{array}$ & Unbound \\
\hline $\begin{array}{l}1 \text { Part MDX, } 1 \text { Part Fine Coffee, } 1 \text { Part } \\
\text { Pullulan }\end{array}$ & Bound \\
\hline $\begin{array}{l}1 \text { Part MDX, } 1 \text { Part Fine Coffee, } 1 \text { Part } \\
\text { GSPS, } 1 \text { Part Pullulan }\end{array}$ & Bound \\
\hline $\begin{array}{l}1 \text { Part MDX, } 1 \text { Part Paprika, } 1 \text { Part } \\
\text { Pullulan }\end{array}$ & Bound \\
\hline $\begin{array}{l}1 \text { Part Paprika, } 1 \text { Part Cumin, } 2 \text { Parts } \\
\text { MDX }\end{array}$ & Bound \\
\hline $\begin{array}{l}1 \text { Part Paprika, } 1 \text { Part Cumin, } 2 \text { Parts } \\
\text { GSPS }\end{array}$ & Semi-Bound \\
\hline 1 Part MDX, 1 Part Cumin & Semi-Bound \\
\hline 1 Part MDX, 1 Part CES & Bound \\
\hline 1 part MDX, 1 Part CES, 1 Part GSPS & Bound \\
\hline 1 Part MDX, 1 Part CES, 1 Part Paprika & Semi-Bound \\
\hline 1 Part CCGSPS, 1 Part CES & Unbound \\
\hline 1 Part MDX, 1 Part HBES & Bound \\
\hline 1 Part MDX, 1 Part HBES, 1 Part PSGS & Bound \\
\hline 1 Part MDX, 1 Part HBES, 1 Part Paprika & Semi-bound \\
\hline 1 Part CCPSGS, 1 Part HBES & Unbound \\
\hline 1 Part MDX, 2 Parts HBES & Semi-Bound \\
\hline 1 Part HBES only & Unbound \\
\hline 1 Part SWM, 1 Part MDX & Semi-Bound \\
\hline 1 Part SWM, 1 Part GSPS & Semi-Bound \\
\hline 1 Part MDX 1 Part SWM, 1 Part Paprika & Unbound \\
\hline 1 Part CCPSGS, 1 Part SWM & Unbound \\
\hline
\end{tabular}

\section{KITCHEN TOOL DESIGN}

For the design part of this study, kitchen tools and formworks were modeled on 3D modeling software Rhinoceros and Grasshopper. Simple geometric forms were integrated into the traditional kitchen tools of Turkish cuisine. The designed kitchen tools are a tray holding a Turkish coffee cup and plate, Turkish delight holder, and a small cup for water (Figure 3). Grasshopper definition allows users to customize their set by editing the parameters of the thickness, width, and height of the tools. This allows a fabricator using the Grasshopper script to 
customize the size of their objects based on their individual needs or the viscosity of their binding mixture.

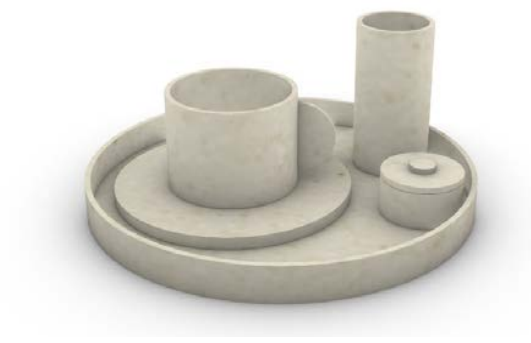

Figure 4: Digital model of kitchen tools

After finalizing the kitchen tool design, the molds for the coffee cup and plate were $3 \mathrm{D}$ printed out of thermoplastic elastomer. The mixture was cast in the formwork for three days. The result of formwork is shown in Figure 4. The final product is rigid with high shape accuracy. Even though the handle of the cup was challenging to fabricate the thin layer of mixture turned out stronger than expected.
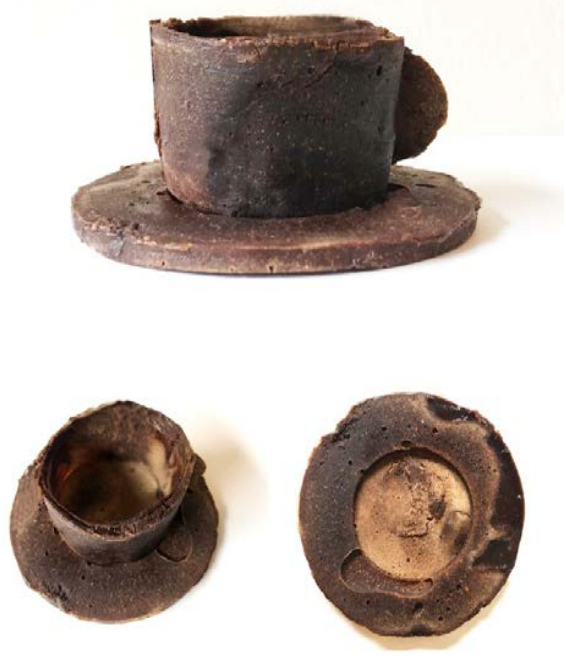

Figure 5: Final product

\section{LIMITATIONS}

Due to the Covid-19 Pandemic and lab closures at the Pennsylvania State University our research team moved to a remote instruction format before experiments concluded. At this time, the most successful powder mixtures were being used to print test bars on the powder-based 3D printed. Unfortunately, we could not test these to $3 \mathrm{D}$ print larger objects. Yet, the successful test-bar 3D prints indicate that positive results are expected in $3 D$ printing full scale objects/kitchen tools.

As a result of this challenge we transitioned to exploring formwork molding as a fabrication method and added glue to the liquid binding mixtures. The addition of glue to the liquid binding mixture results in a much higher likelihood of achieving a bound result in a test because glue is a known adhesive, and its full mixture with the powder and liquid elements creates more even distribution. Since a gluebased form molded mixture is more likely to bind successfully, it would have been interesting to retest all 39 powder mixtures to see if the results would differ. However, without access to our materials and lab equipment such as a dehydrator, we were unable to rerun the tests. Gluebased liquid binding may result in a higher rate of success with mixtures which were previously classified as "unbound."

\section{DISCUSSION}

The transition from a powder printing to formwork molding method of fabrication increased the number of variables and experimental factors in our research, particularly by opening up the possibility of previously un-bound powders being bound with glue. Ideally, the next steps in our research would be to retest each of the powder mixtures in a glue-bound formwork molded application. Likewise, with a return to the lab post-Covid-19, the next step for our 3D printing based research would be to begin printing full-scale kitchen tool prototypes with our most successful maltodextrin mixtures.

While the limitations caused by the Covid-19 pandemic hindered our research team's initial intentions, the concept of using formworks to mold objects out of food waste makes the making process of waste-tooling more accessible to individuals who may not have access to a $3 \mathrm{D}$ printer or fabrication lab. For example, most households owning a coffee or spice grinder could process a variety of food waste into formable powders. Glue, water, and isopropyl alcohol are also easily accessible ingredients to the average consumer. Form-molds could also be fashioned from imprinting household objects into clay, or foam. Likewise, the dehydrator environment could be easily replicated by setting a home oven to its lowest temperature and convection mode. These possibilities democratize waste-tooling as a creative making process available to individuals outside of the design and digital fabrication community. Furthermore, the concept of using household food waste as a material for making rather than destruction could be an educational tool used to teach children about sustainability and a circular economy.

The process of waste-tooling, whether in the form of 3D printing, or form molding, presents an opportunity for designers or consumers to repurpose food waste for creative making purposes. Though the fabrication of novel kitchen tools with food waste has limits to its practical use, the novelty of the objects themselves is a demonstration of sustainable making methods. Waste-tooling can become both a making process for designers and an educational and creative tool for students and individuals, demonstrating a unique approach to sustainable design. 


\section{ACKNOWLEDGEMENTS}

The authors would like to acknowledge the contributions of Tazrin Islam and Özgüç Bertuğ Çapunaman in this project. Both are graduate students of architecture at the Pennsylvania State University. They provided critical guidance on employing food waste in design processes, as well as on developing the 3D printing framework for waste-tooling. The study has been conducted at ForMat Lab (Form and Matter Lab).

\section{REFERENCES}

Canavarro, Vasco., Rangel, Barbara \& Alves, Jorge. 2017 "Coffee Powder Reused as a Composite Material." Materials Design and Applications. Vol. 65;65.; Cham: Springer International Publishing. doi:10.1007/978-3-31950784-2.

Clark, James. 2017. "Introduction." In: Morone P., Papendiek F., Tartiu V. (eds) Food Waste Reduction and Valorisation. Springer, Cham
Eliche-Quesada, D., L. Pérez-Villarejo, F. J. Iglesias-Godino, C. Martínez-García, \& F. A. Corpas-Iglesias. 2011 "Incorporation of Coffee Grounds into Clay Brick Production." Advances in Applied Ceramics: Cement and Concrete Research 110 (4): 225-232.

Jagdale, P., Ziegler, D., Rovere, M., Tulliani, J. \& Tagliaferro A. 2019. "Waste Coffee Ground Biochar: A Material for Humidity Sensors." Sensors. doi:10.3390/s19040801

Melikoglu, M., Lin, C. \& Webb, C. 2013. "Analysing global food waste problem: pinpointing the facts and estimating the energy content." Open engineering. doi:10.2478/s13531012-0058-5

Rael, Ronald, and Virginia San Fratello. 2018. Printing architecture: innovative recipes for 3D printing.

Walters, P., Huson, D., \& Southerland, D. 2011. " Edible 3D Printing." In Society for Imaging Science and Technology (Ed.), NIP27: International Conference on Digital Printing Technologies and Digital Fabrication 2011, 819-822. The Society for Imaging Science and Technology 